\title{
Analysis of Network Structure of Urban Bike-Sharing System: A Case Study Based on Real-Time Data of a Public Bicycle System
}

\author{
Yi Yao ${ }^{1}$, Yifang Zhang ${ }^{1, *}$, Lixin Tian ${ }^{1}$, Nianxing Zhou ${ }^{2}$, Zhilin $\mathrm{Li}^{3}$ and Minggang Wang ${ }^{1,4}$ \\ 1 School of Mathematical Sciences, Nanjing Normal University, Nanjing 210023, China; \\ 05302@njnu.edu.cn (Y.Y.); tianlixin@njnu.edu.cn (L.T.); magic821204@sina.com (M.W.) \\ 2 School of Geography, Nanjing Normal University, Nanjing 210023, China; zhounianxing@263.net \\ 3 Department of Mathematics, North Carolina State University, NC 27695, USA; zhilin@ncsu.edu \\ 4 Department of Mathematics, Nanjing Normal University Taizhou College, Taizhou 225300, China \\ * Correspondence: 180938024@stu.njnu.edu.cn
}

Received: 12 July 2019; Accepted: 27 September 2019; Published: 30 September 2019

\begin{abstract}
To better understand the characteristics of a bike-sharing system, we applied complex network methods to analyze the relationship between stations within the bike-sharing system. Firstly, using Gephi software, we constructed the public bicycle networks of different urban areas based on the real-time data of the Nanjing public bicycle system. Secondly, we analyzed and compared degree, strength, radiation distance, and community structure of the networks to understand the internal relations of the public bicycle system. The results showed that there were many stations with low usage of public bicycles. Furthermore, there was a geographical division between high-demand and low-demand areas for public bicycles. The usage of public bicycles at a station was not only related to land use but also related to the usage of bicycles at stations nearby. Moreover, the average service coverage of the public bicycle system was consistent with the original intention of "the first and last mile", and public bicycles could meet different travel needs.
\end{abstract}

Keywords: sustainable mode of transportation; bike-sharing system; public bicycle; complex network; network structure

\section{Introduction}

Bike-sharing systems (BSSs) not only facilitate people with the trouble of "the first and last mile" but also provide them with a sustainable and carbon-free mode of transportation. In 1965, an NGO called Provo established a public bicycle system (PBS) to reduce air pollution and relieve traffic congestion in Amsterdam, which is regarded as the prototype of BSSs [1].

With economic booming and social modernization, bicycles are not the top choice in most countries. Nevertheless, due to increasingly serious air pollution and traffic congestion, public bicycle, a station-based bike-sharing, has gradually become a significant transportation alternative once again. However, untimely rebalancing operations and unreasonable station distributions not only reduce users' satisfaction but also increase the scheduling and maintenance costs, which results in waste of public resources. Therefore, studies on PBSs are beneficial to solve the issue of "unavailable bicycles and unavailable docks" and can improve the social and economic benefits of PBSs.

Scholars have carried out a lot of research on BSSs and achieved fruitful results. Characteristics of users and stations, influencing factors, and built environment are all main research contents. Users' gender [2-7], age [3,6-8], income and education [2,5,6,9,10], weather conditions [11-13], infrastructure construction, population density, built environment [7,12-19], and relationship with other means of transportation [20-33] have been confirmed to affect the usage of bike-sharing. On the other hand, 
in order to solve the problem of rebalancing, optimization of BSSs has also become another hot issue [34-43]. As far as research methods are concerned, statistical methods such as correlation analysis, clustering analysis, and regression analysis are adopted to analyze characteristics and influencing factors $[3,7,9,13,14,19,20,22,23,44]$, and optimization algorithms are used to solve rebalancing operations for BSSs [35,38-40,42,43].

The existing researches mainly discuss BSSs from the aspects of the relationship between BSSs and external environments, while studies from the perspective of the relationship between internal stations of BSSs are insufficient. To fill this gap, we built public bicycle networks (PBNs) using Gephi software according to complex network methods, aiming to analyze internal correlation characteristics of BSSs.

The remainder of the paper is organized as follows. Section 2 reviews the relevant literature. Section 3 provides the data and methodology, and Section 4 analyzes the results. Lastly, Section 5 presents conclusions.

\section{Literature Review}

\subsection{Relationship between BSSs and External Environments}

Relationship between BSSs and external environments is a hot issue.

Weather conditions are an important influencing factor for the use of public bicycles. More bicycles were used in good weather, while rain, snow, low temperature, and gales resulted in less use [11-13].

Infrastructure construction and population also profoundly influence the use of bike-sharing. In Montreal, increasing the number of stations played a more active role in cycling than increasing the number of parking piles [12]. More public bicycle lanes promoted the use of public bicycles [14]. In general, station capacity, zonal population, employment density, commercial land, and daily life places nearby were positively correlated with cycling [7,13,15-19].

The relationship between BSSs and other transportation systems is getting more and more attention. Scholars analyzed the impact of bike-sharing on walking, cars, public transportation, and subways. Many results showed that bike-sharing replaced walking and public transportation to some extent, and bike-sharing was expected to play a more important role in reducing car use [2,20,21,25-29]. Subway stations were important starting and ending stations of BSSs, and the increase of cycling flow would lead to an increase of average daily subway flow [21,23,32]. Some researchers found that sudden change in public transport services, such as a public transit disruption or a strike, would affect the use of bicycles significantly [30,31]. As for free-floating BSSs and station-based BSSs, Li et al. pointed out that the former had a greater effect on the latter especially on weekdays and on young people [24]. Luo et al. found that greenhouse gas emissions factor of free-floating BSSs was $82 \%$ higher than station-based BSSs based on life cycle assessment [33].

\subsection{Internal Relationship of BSSs}

Some studies of BSSs carried out clustering analysis on the stations, which essentially explored the relationship between the stations and also the internal relationship of the systems. The usage pattern of stations was identified by the clustering method, and the clustering results were influenced by station locations and socioeconomic situations [7,23,45-47]. More bike-sharing movements were observed within a cluster than between clusters in Lyon [48]. However, clustering analysis mainly distinguishes the similarity of stations and does not highlight the relationship between them.

Recently, some scholars have begun to focus on BSSs using network analysis methods. Rixey pointed out that station network effects were extremely important to ridership levels, with a robust, statistically significant relationship within systems. Station network variables were put forward to test the effects of public bicycle station network density, distribution, and size on cycling. The results revealed that there was a positive correlation between the number of stations within $4800 \mathrm{~m}$ of a given station and the number of people cycling monthly [9]. Saberi et al. combined geospatial methods with complex network methods to better understand the interdependence between BSSs and public 
transportation systems in London [31]. Austwick et al. explored BSSs in different cities by network analysis, and they found that the strength rank curve for the top 50 stations in each system displayed a similar scaling law. Furthermore, community detection in the network could identify local use [49]. Lin et al. proposed a novel graph convolutional neural network with data-driven graph filter model to predict station-level hourly demand with fairly good prediction accuracy. Graph network analysis showed that this model could not only gather more information from more stations but also utilize more underlying correlations between stations [50].

Although the existing research has provided us a lot of insights, there is potential to deepen the knowledge of BSSs. (1) The relationship between BSSs and external environment has been more in-depth, while the internal correlation of BSSs needs to be expanded. Complex network analysis is applied to study the internal correlation between nodes according to their connection relationship, which is relatively under-utilized to understand BSSs [49]. (2) How to construct a bike-sharing network and select appropriate statistical analysis indicators is an important issue that needs to be discussed. As research on the internal relationship of BSSs by complex network analysis is still inadequate, this problem is the premise of understanding the characteristics of BSSs. (3) How to select representative areas for comparative analysis to gain an in-depth understanding of BSSs is also another problem that we should pay much attention to. Because of different population density, employment density, built environment, and land use in different areas, characteristics of BSSs also vary. That is, conclusions and suggestions put forward according to the information in certain regions are not necessarily applicable to other regions. As a result, regional information should be gathered for system operators to possess a more comprehensive knowledge of BSSs.

According to the spatiotemporal real-time data of the PBS in Nanjing, we first constructed the public bicycle networks (PBNs) of different urban areas with Gephi software. Then, we not only analyzed statistical indicators such as degree and strength but also defined "radiation distance". Finally, we analyzed internal correlation characteristics between stations and compared characteristics in different regions.

\section{Data and Methodology}

We chose Nanjing PBS in China as our case study. Nanjing is the center of politics, economy, education, and culture in Eastern China and also the provincial capital of Jiangsu Province, with an area of $6587.02 \mathrm{~km}^{2}$. At the end of 2016, the total population was 8.27 million with the urban population density 1484 people $/ \mathrm{km}^{2}$. There were 10,402 public transport vehicles in operation, with a network of 10,476.3 km in length and a total of 1776 million passengers, ranked 6th in China in 2016. Behind the economic prosperity and the development of modern transportation, air pollution cannot be ignored. In 2016, the annual average concentration of pm10 was $0.085 \mathrm{mg} / \mathrm{m}^{3}$, with exhaust emissions of 773.482 billion $\mathrm{m}^{3}$ and soot emissions of 48,600 tons [51]. Therefore, the study of Nanjing PBS is of positive significance to improve the efficiency of PBSs in modern metropolis with high population density, heavy traffic, and air pollution.

Nanjing PBS has more than 600 stations almost covering the main city since Nanjing Public Bicycle Company was founded in 2015. People pay a deposit for a public bicycle card. The charge is zero for the first two hours, one Chinese yuan for the third hour, and three Chinese yuan per hour for the fourth hour and above. A user picks up a bicycle at a station and returns it in the parking pile at the destination station to complete this trip.

\subsection{Data}

Nanjing Public Bicycle Company provided us with 662,007 anonymous daily data from 20 March 2016 to 26 March 2016, including user ID, renting (returning) stations, renting (returning) time, longitude and latitude of returning stations (see Table 1). Some situations such as bicycle and timer malfunctions would lead to inaccurate cycling time records. Thus, the data that indicated less than 2 min or more than $2 \mathrm{~h}$ usage were excluded, and the number of actual valid data was 593,582. In this week, 131,695 
users used public bicycles, with an average of 4.5 times, the average duration of $15.77 \mathrm{~min}$, and the average cycling distance of $1.43 \mathrm{~km}$, which was consistent with "the first and last mile".

Table 1. Sample data of Nanjing public bicycle system (PBS).

\begin{tabular}{ccccccc}
\hline User ID & Renting Time & Returning Time & $\begin{array}{c}\text { Renting } \\
\text { Station }\end{array}$ & $\begin{array}{c}\text { Returning } \\
\text { Station }\end{array}$ & $\begin{array}{c}\text { Longitude of } \\
\text { Returning } \\
\text { Station }\end{array}$ & $\begin{array}{c}\text { Latitude of } \\
\text { Returning } \\
\text { Station }\end{array}$ \\
\hline $10^{* * *}$ & $2016 / 3 / 200: 09$ & $2016 / 3 / 200: 20$ & 1118228 & 1216847 & 118.7629 & 32.03357 \\
$22^{* * *}$ & $2016 / 3 / 2116: 18$ & $2016 / 3 / 2116: 24$ & 1118406 & 1119129 & 118.7621 & 32.04811 \\
$10^{* * *}$ & $2016 / 3 / 2419: 51$ & $2016 / 3 / 2419: 59$ & 1119305 & 1211847 & 118.7544 & 32.041 \\
\hline
\end{tabular}

Gulou District is the central area and also the political, economic, educational, and cultural center of Nanjing. The resident population of Gulou District is 1,249,400, ranked 1st in the six main urban districts of Nanjing, and the area is $53 \mathrm{~km}^{2}$, with a population density of 23,574 people $/ \mathrm{km}^{2}$. In 2016, the total production value of Gulou District was 112.303 billion Chinese yuan, ranked 1st, and the per capita annual disposable income was 54,791 Chinese yuan. High population density and employment density lead to high demand for public bicycles. Qixia District is located in a remote area with a large area and low population density. The resident population of Qixia District is 693,300, ranked 3rd, and the area is $395.44 \mathrm{~km}^{2}$, with a population density of 1753 people/ $\mathrm{km}^{2}$. In 2016, the total production value of Qixia District was 92.723 billion Chinese yuan, ranked 2nd, and the per capita annual disposable income was 48,379 Chinese yuan. Low population density may be the main reason for low demand for public bicycles. Gulou District and Qixia District, one as the center of economics and politics and the other as the emerging district of culture and education, are different in geographical location, regional functions, distribution of stations, and demand for public bicycles. Therefore, it is reasonable to select these two districts to analyze and compare the internal correlation characteristics of PBNs.

\subsection{Complex Network Theory}

Complex network theory explores topological structures and properties of a network utilizing graph theory and statistical physics, which can show the nature of the network without depending on the specific location of nodes and specific shape of edges. In a network, nodes represent research objects, and edges connecting two nodes represent their relationship. Now, complex network theory has been successfully applied in financial markets [52-54], transportation systems [9,31,49,50,55-57], and energy fields [58-61].

We treat a station as a node. If a user rents a public bicycle at station $A$ and returns it to station $B$, there is a directed edge pointing from $A$ to $B$. The weight of this edge is equal to the number of cycling records from $A$ to $B$, which can show how close the relationship between $A$ and $B$ is. Hence, a PBN is a directed weighted network.

\subsubsection{Degree}

For a PBN, public bicycles rented from station $i$ are returned to various destination stations, and the number of these destination stations is defined as the out-degree $k_{i}^{\text {out }}$ of node $i$. Public bicycles rented from various origin stations are returned to station $i$, and the number of these origin stations is defined as the in-degree $k_{i}^{\text {in }}$ of node $i$. The calculation formulas of $k_{i}^{\text {out }}$ and $k_{i}^{\text {in }}$ are as follows:

$$
k_{i}^{\text {out }}=\sum_{j=1}^{N} a_{i j}, \quad k_{i}^{\text {in }}=\sum_{j=1}^{N} a_{j i}
$$

where $a_{i j}$ denotes an element of adjacency matrix, that is, if there is a directed edge from station $i$ to station $j, a_{i j}=1$; otherwise, $a_{i j}=0 . N$ represents the number of nodes. 


\subsubsection{Strength}

For a PBN, the out-strength $s_{i}^{\text {out }}$ represents the number of public bicycles rented from station $i$, and the in-strength $s_{i}^{i n}$ represents the number of public bicycles returned to station $i$. The calculation formulas of $s_{i}^{\text {out }}$ and $s_{i}^{\text {in }}$ are as follows:

$$
s_{i}^{\text {out }}=\sum_{j=1}^{N} w_{i j}, \quad s_{i}^{\text {in }}=\sum_{j=1}^{N} w_{j i}
$$

where $w_{i j}$ represents the weight of the edge from station $i$ to station $j$.

\subsubsection{Radiation Distance}

Compared with general complex networks, PBNs have their own way of calculating path length. For example, if one user rents a public bicycle from station $A$ and returns it to station $B$ and another user rents one from station $B$ and returns it to station $C$, there is a path from station $A$ to station $C$ according to the concept of "path" in complex network theory. However, we cannot explain this path as a user starting from station $A$ and going to station $C$ via station B. Furthermore, there may be no records renting one from station A and returning it to station C. Therefore, applying "path length" of complex network theory to PBNs may be of no significance. As a result, we define "radiation distance" to measure the distance between stations (nodes).

In a PBN, we define the radiation distance from station $\mathrm{A}$ to station $\mathrm{B}$ as the actual distance between them, and the radiation distance of station $\mathrm{A}$ is the average radiation distance from station $\mathrm{A}$ to the other stations. Hence, the radiation distance of a PBN is the average radiation distance of all the stations.

\subsubsection{Community Structure}

In a network, nodes in the same community are closely connected. Modularity $Q$ is used to evaluate the quality of community division, and community division with the maximum value of modularity is optimal. For a directed weighted complex network, modularity is calculated as follows:

$$
Q=\frac{1}{W} \sum_{i, j}\left(w_{i j}-\frac{s_{i}^{\text {out }} s_{j}^{\text {in }}}{W}\right) \delta\left(M_{i}, M_{j}\right)
$$

where $W$ is the sum of all the weights, $M_{i}$ is the community that station $i$ belongs to and $M_{j}$ is the community that station $j$ belongs to. If station $i$ and station $j$ belong to the same community, $\delta\left(M_{i}, M_{j}\right)=1$, otherwise, $\delta\left(M_{i}, M_{j}\right)=0$.

\section{Results}

\subsection{The Construction of the PBN}

We first treated each public bicycle station in Gulou District as a node, and then added the stations in other districts that had public bicycle renting or returning with the nodes into the network. Hence, there were totally 587 stations (nodes) in the PBN of Gulou District. There were directed edges between the nodes, and the weights were the number of public bicycles rented or returned.

\subsection{The Analysis of Out-Degree and In-Degree}

The average in-degree of the PBN of Gulou District was 57 with the maximum being 287. Since the in-degree of each station was numerically dispersed, we performed interval segmentation to better understand its distribution. We first divided the values of in-degree by the interval length of 20 . Then, we considered the integer closest to the weighted average of in-degree and the number of the 
stations within the interval as the representative of the interval value. In this way, we got the in-degree distribution, see Figure 1a. In a log-log plot, the least square estimation was applied to estimate the in-degree distribution, and the regression equation was $y=-1.2221 x+2.3808$ with the coefficient of determination $R^{2}=0.897$, which showed a good fitting effect (see Figure 1b).

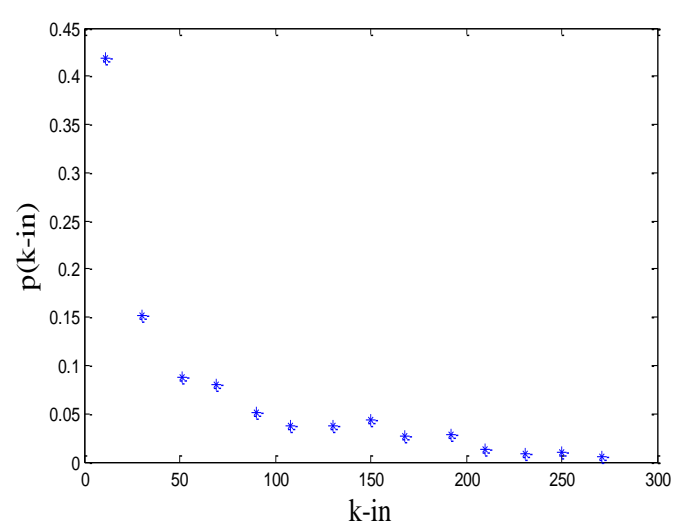

(a)

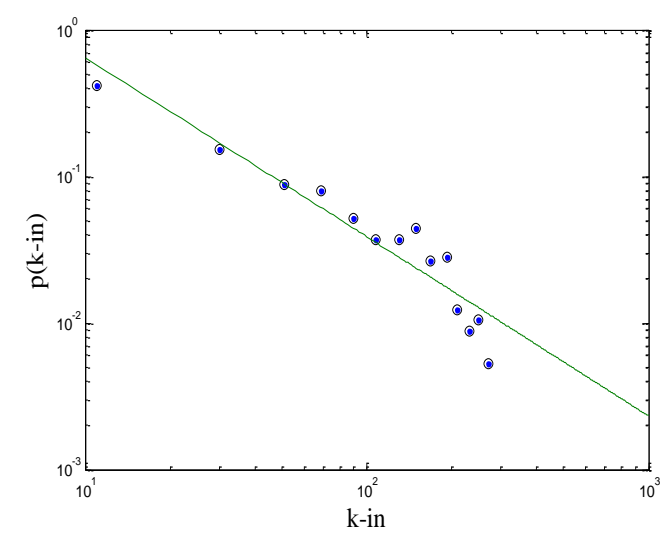

(b)

Figure 1. (a) The in-degree distribution of the public bicycle network (PBN) of Gulou District; (b) the in-degree distribution estimation in a log-log plot.

The average out-degree of the PBN of Gulou District was 57 with the maximum being 289 . Figure 2a shows the out-degree distribution. In a $\log -\log$ plot, the regression equation was $y=-1.1262 x$ +1.9299 with the coefficient of determination $R^{2}=0.876$ (see Figure 2b). As a result, the in-degree and out-degree distribution of the PBN of Gulou District followed the power-law distribution with the power exponents of 1.22 and 1.13, respectively, which were smaller than power exponents of scale-free networks between 2-3. According to the data, there were 245 stations with an in-degree of less than 20, accounting for $41.7 \%$ of all the stations, and there were 235 stations with an out-degree of less than 20 , accounting for $40.0 \%$. These results indicated that the percentage of the stations with small in-degree or out-degree was lower than that of typical scale-free networks.



(a)

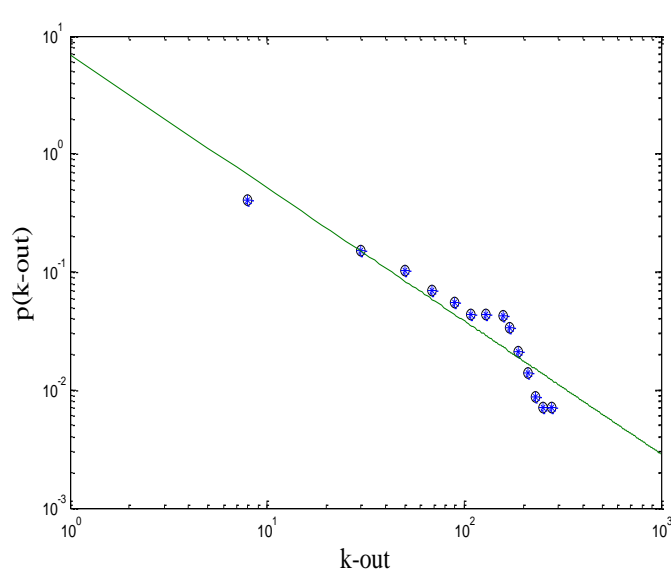

(b)

Figure 2. (a) The out-degree distribution of the PBN of Gulou District; (b) the out-degree distribution estimation in a log-log plot.

There were 225 stations (nodes) in the PBN of Qixia District. The average in-degree and out-degree were both 11, and the maximum in-degree and out-degree were 93 and 87, respectively, which were smaller than those of the PBN of Gulou District. Geographically, Gulou District borders Qixia, Xuanwu, 
Qinhuai, Yuhuatai, and Jianye districts, while Qixia District borders Gulou and Xuanwu districts. From the perspective of station size, there were 175 stations in Gulou District and 41 stations in Qixia District. Therefore, there were big gaps between the two PBNs in station connections and station size.

The in-degree distribution and out-degree distribution of the PBN in Qixia District were similar to long tail distribution (see Figure 3) and they followed the power-law distribution with the power exponents of 1.33 and 1.21, respectively. The power exponents were larger than those of the PBN of Gulou District, which probably meant idle situation of stations in Qixia District was more serious than that in Gulou District.
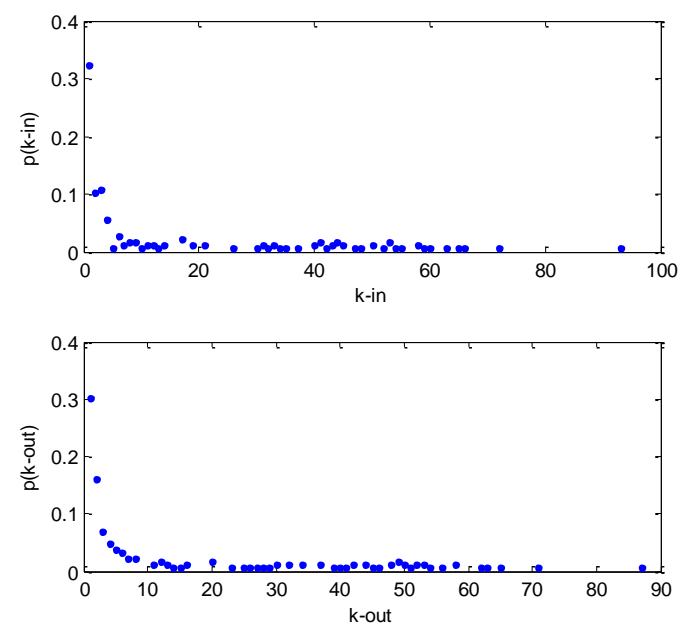

Figure 3. The in-degree and out-degree distribution of the PBN of Qixia District.

\subsection{The Analysis of Out-Strength and In-Strength}

Table 2 lists the top ten stations of the PBN of Gulou District based on in-strength and based on out-strength, and the number in brackets after the station name is the station number. Nine of the top ten based on in-strength and the top ten based on out-strength were the same except Longjiang Stadium East Station and Mingcheng Century Park East Gate Station. At the same time, Table 3 lists the bottom ten stations, and the number in brackets after the station name is the station number. The bottom ten based on in-strength and the bottom ten based on out-strength were nearly the same except the "724 Institute" Station and Shengshi Garden Station. This result indicated that renting flow and returning flow at a station was almost equivalent. Moreover, the strength of the top ten was much stronger than that of the bottom ten, which showed that the usage of public bicycles at different stations varied greatly.

Figure 4 shows the geographical distribution of these stations. The red and purple marks correspond to the top ten and the bottom ten stations in Tables 2 and 3, respectively. There are 11 different stations in Table 2, so there are 11 top ten stations in Figure 4 without distinguishing in-strength from out-strength, and the same is true for the bottom ten. There were regional differences in the use of public bicycles. The bottom ten stations were mainly distributed in the north of Metro Line 4, while the top ten were in the south. According to the land use, the commercial land, for example, Xinjiekou Huaqiao Road and Fenghuang business area as well as other cultural and recreational facilities, sports facilities, and educational institutions were concentrated in the south of Metro Line 4. The distribution of stations may indicate that areas close to central business districts had a higher demand for public bicycles due to their high population density and employment density, that is, the more social and economic activities, the more use of public bicycles. Hence, adequate and timely supply of public bicycles around these areas is the priority. 
Table 2. The top ten stations of the PBN of Gulou District.

\begin{tabular}{|c|c|c|c|c|}
\hline No. & Station & In-Strength & Station & Out-Strength \\
\hline 1 & $\begin{array}{l}\text { Qingliangmen Suguo } \\
\text { Supermarket(1) }\end{array}$ & 3111 & $\begin{array}{l}\text { Qingliangmen Suguo } \\
\text { Supermarket(1) }\end{array}$ & 3262 \\
\hline 2 & Suning Global Trade City(2) & 2851 & Hetai International Building(5) & 2758 \\
\hline 3 & $\begin{array}{c}\text { International Service Outsourcing } \\
\text { Building(3) }\end{array}$ & 2817 & Yingchunli West Gate(4) & 2647 \\
\hline 4 & Yingchunli West Gate(4) & 2723 & $\begin{array}{l}\text { Nanjing University of Chinese } \\
\text { Medicine South Station }(9)\end{array}$ & 2646 \\
\hline 5 & Hetai International Building(5) & 2468 & Suning Global Trade City(2) & 2600 \\
\hline 6 & Jiaheyuan(6) & 2390 & $\begin{array}{c}\text { International Service Outsourcing } \\
\text { Building(3) }\end{array}$ & 2387 \\
\hline 7 & $\begin{array}{l}\text { Zhonghai Fenghuangxian South } \\
\text { Gate(7) }\end{array}$ & 2237 & Jiaheyuan(6) & 2142 \\
\hline 8 & National University Science Park(8) & 2178 & $\begin{array}{l}\text { Zhonghai Fenghuangxian South } \\
\text { Gate(7) }\end{array}$ & 2090 \\
\hline 9 & $\begin{array}{l}\text { Nanjing University of Chinese } \\
\text { Medicine South Station }(9)\end{array}$ & 2136 & $\begin{array}{l}\text { Mingcheng Century Park East } \\
\text { Gate(11) }\end{array}$ & 2043 \\
\hline 10 & Longjiang Stadium East Station(10) & 2104 & National University Science Park(8) & 1871 \\
\hline
\end{tabular}

Table 3. The bottom ten stations of the PBN of Gulou District.

\begin{tabular}{ccccc}
\hline No. & Station & In-Strength & Station & Out-Strength \\
\hline 1 & No. 5 Ningxia Road(1) & 104 & Qingjiang Xiyuan North Gate(2) & 105 \\
2 & Qingjiang Xiyuan North Gate(2) & 122 & No. 5 Ningxia Road(1) & 113 \\
3 & Tianfeigong Primary School(3) & 159 & Tianfeigong Primary School(3) & 155 \\
4 & Biancheng Shijia West Gate(4) & 163 & Crown Diamond Double Star & 187 \\
5 & No.35 Xikang Road(5) & 173 & South(7) & 191 \\
6 & Xikang Hotel(6) & 192 & Biancheng Shijia West Gate(4) & 194 \\
7 & Crown Diamond Double Star & 219 & Gate 4 of Tianzhenghubin(10) & 202 \\
8 & South(7) & 219 & No.35 Xikang Road(5) & 206 \\
9 & 724 Institute(8) & 219 & Shengshi Garden(11) & 206 \\
10 & Gate 1of Tianjinxincun(9) & 226 & Gate 1of Tianjinxincun(9) & 249 \\
\hline
\end{tabular}

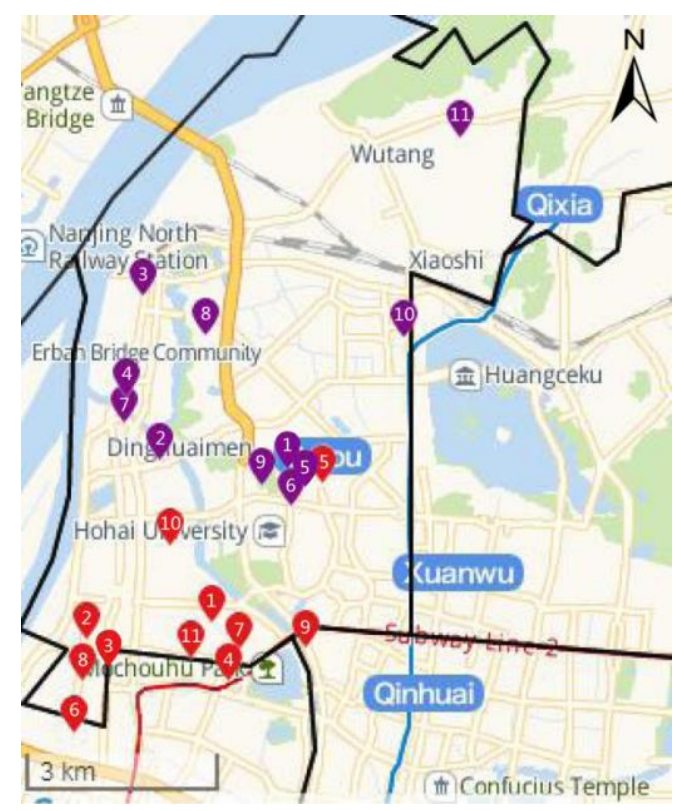

Figure 4. The distribution of the top ten and the bottom ten stations of the PBN of Gulou District.

We should point out that many stations with strong strength were close to subway stations, such as Jiaheyuan Station and Jiqingmen Street Subway Station, Yingchunli West Gate Station and 
Hanzhongmen Subway Station, Nanjing University of Chinese Medicine South Station and Shanghai Road Subway Station, which indicated that subway stations were important starting and destination stations for cycling. Therefore, the construction of bicycle stations around subway stations is an important measure to promote the usage of public bicycles.

It was worth noting that there was still low usage of public bicycles even in densely populated areas. There were several residential areas around Qingjiang Xiyuan North Gate Station, and Qingjiang Xiyuan West Gate Station was also nearby. According to the records, almost $60 \%$ of the stations associated with these two stations were the same. In fact, Qingiiang Xiyuan West Gate Station was closer to the bus stop and subway station, so the usage of public bicycles was higher than that of Qingjiang Xiyuan North Gate Station. Except for station location, competitive relationship with other stations also affected the usage of public bicycles. Therefore, unreasonable station setting not only reduced the efficiency of PBSs but also led to a waste of public resources.

In directed weighted networks, nodes with strong strength are worth studying. We analyzed Qingliangmen Suguo Supermarket Station, which had the strongest in-strength and out-strength of the PBN of Gulou District.

Figure 5 shows the station distribution around Qingliangmen Suguo Supermarket Station. On the one hand, Mochou Lake Subway Station West Station, Lixue Primary School Station, Huayang Jiayuan North Gate Station, and Yingchunli West Gate Station contributed the most to the in-strength of Qingliangmen Suguo Supermarket Station. On the other hand, the most frequent destinations of this station were Mochou Lake Subway Station West Station, Huayang Jiayuan East Gate Station, Lixue Primary School Station, Jinxin Garden North Gate Station, and Suning Qianqiu Garden East Gate Station. The results showed that if an area where supermarkets, residential areas, subway stations, and schools were concentrated, it was always the main area for the use of public bicycles, which was consistent with the existing research results [7]. Furthermore, in-strength and out-strength of the stations around Qingliangmen Suguo Supermarket Station were above the average level of the network. The observed data showed that the usage of public bicycles at a station was not only related to the built environment but also affected by the usage of bicycles at stations nearby. Ensuring the availability of public bicycles and parking piles of these key stations would have a direct impact on the use of public bicycles throughout the whole area.

As a popular supermarket in Gulou District, Qingliangmen Suguo Supermarket is adjacent to 10 residential areas, including Huayang Jiayuan, Jinxin Garden, Yingchunli, and Suning Qianqiu Garden, and many users cycle to and from the communities and the supermarket every day. Table 4 lists the comparison of the distances and time required from these communities to the supermarket by different travel modes. The comparison indicated that public bicycle was a time-saving means of transportation when the distance was about $1000 \mathrm{~m}$. Convenience, speed, and economy are the advantages of public bicycles for short-distance travel.

Table 4. Comparison of different travel modes.

\begin{tabular}{ccccccccc}
\hline $\begin{array}{l}\text { Travel } \\
\text { Mode }\end{array}$ & $\begin{array}{c}\text { Distance from } \\
\text { Huayang } \\
\text { Jiayuan } \\
\text { (Meter) }\end{array}$ & $\begin{array}{c}\text { Travel } \\
\text { Time } \\
\text { (Minute) }\end{array}$ & $\begin{array}{c}\text { Distance } \\
\text { from Jinxin } \\
\text { Garden } \\
\text { (Meter) }\end{array}$ & $\begin{array}{c}\text { Travel } \\
\text { Time } \\
\text { (Minute) }\end{array}$ & $\begin{array}{c}\text { Distance } \\
\text { from } \\
\text { Yingchunli } \\
\text { (Meter) }\end{array}$ & $\begin{array}{c}\text { Travel } \\
\text { Time } \\
\text { (Minute) }\end{array}$ & $\begin{array}{c}\text { Distance from } \\
\text { Suning Qianqiu } \\
\text { Garden } \\
\text { (Meter) }\end{array}$ & $\begin{array}{c}\text { Travel } \\
\text { Time } \\
\text { (Minute) }\end{array}$ \\
\hline Walking & 570 & 8 & 1000 & $>10$ & 1200 & $>10$ & 960 & $>10$ \\
Driving & 1800 & 9 & 1300 & 6 & 1000 & 6 & 1500 & 9 \\
Cycling & 600 & 4 & 1100 & 7 & 1000 & 6 & 1000 \\
\hline
\end{tabular}

The top ten stations of the PBN of Qixia District based on in-strength were also the top ten stations based on out-strength (see Table 5), and the same was true for the bottom ten (see Table 6). Figure 6 shows the distribution of these stations. The red and purple marks correspond to the top ten and the bottom ten in Tables 5 and 6, respectively. Most of the top ten stations were located around Maigaoqiao Subway Station and along Heyan Road, the major economic area in Qixia District. In particular, the in-strength and out-strength of Gate 1 of Maigaoqiao Subway Station were significantly stronger 
than the other stations due to the origin station of Metro Line 1. At the same time, six stations within $1200 \mathrm{~m}$ around Maigaoqiao Subway Station had strong in-strength and out-strength, forming an area of high demand for public bicycles. Among the six stations, Qiancaomingyuan South Station and Jinghongyuan South Station contributed the most to in-strength and out-strength, which indicated that public bicycle was an effective means of transportation between communities and important transportation hubs. As a result, public bicycles can bring people more convenience if the connection of public bicycle stations with other transportation stations is well projected in areas with sparse distribution of public transportation. In addition, the usage of public bicycles in Qixia District was less than that in Gulou District.

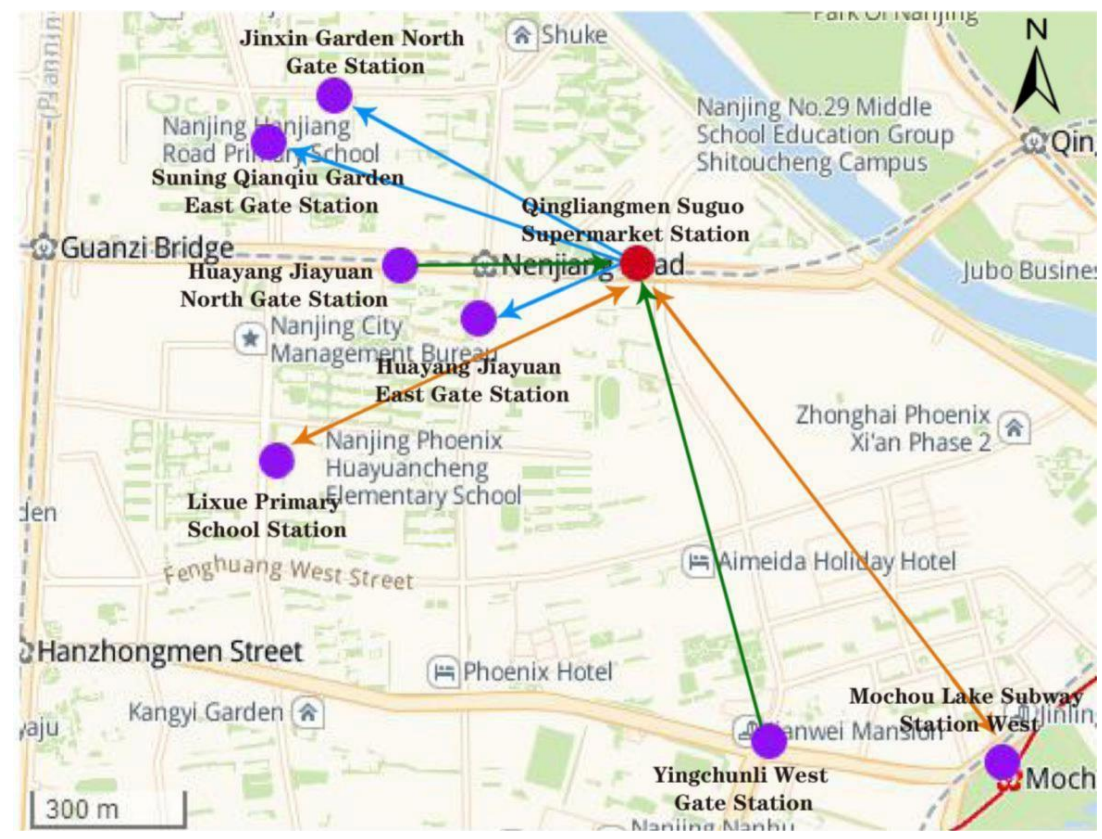

Figure 5. The station distribution around Qingliangmen Suguo Supermarket Station.

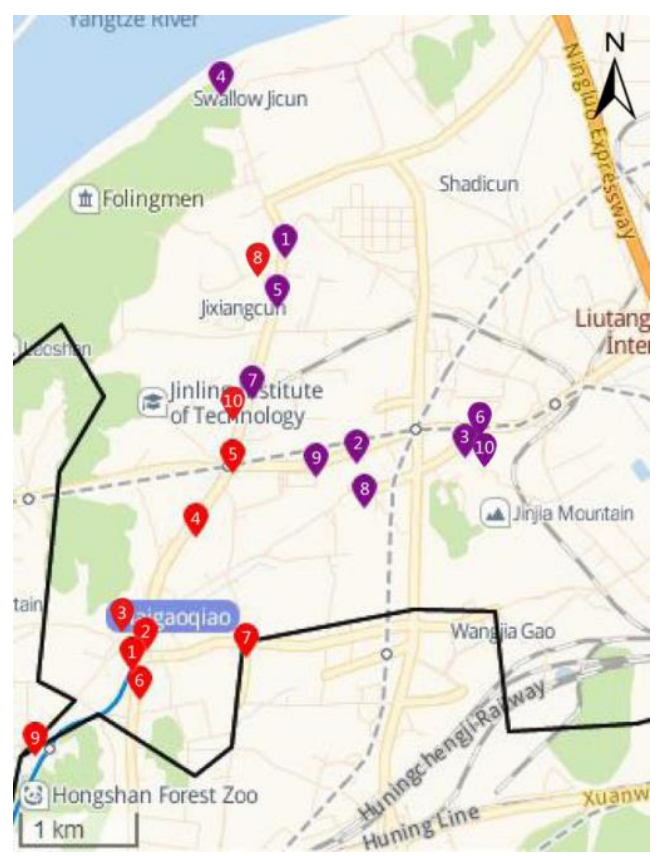

Figure 6. The distribution of the top ten and the bottom ten stations of PBN of Qixia District. 
Table 5. The top ten stations of the PBN of Qixia District.

\begin{tabular}{ccccc}
\hline No. & Station & In-Strength & Station & Out-Strength \\
\hline 1 & Gate 1of Maigaoqiao Subway(1) & 1727 & Gate 1of Maigaoqiao Subway(1) & 1753 \\
\hline 2 & Maigaoqiao Bus Station(2) & 1063 & $\begin{array}{c}\text { Maigaoqiao Zijin Rural Commercial } \\
\text { Bank(3) }\end{array}$ & 1003 \\
\hline 3 & $\begin{array}{c}\text { Maigaoqiao Zijin Rural Commercial } \\
\text { Bank(3) }\end{array}$ & 1037 & Maigaoqiao Bus Station(2) & 970 \\
\hline 4 & Heyan Road Community East(4) & 862 & Heyan Road Community East(4) & 912 \\
\hline 5 & $\begin{array}{c}\text { Xiaozhuang International Plaza } \\
\text { West(5) }\end{array}$ & 818 & Mufu Mountain Villa(10) & 808 \\
\hline 6 & $\begin{array}{c}\text { Jiangsu Province Hospital on } \\
\text { Integration of Chinese and Western } \\
\text { Medicine West(6) }\end{array}$ & 714 & Shengli Village East(8) & 788 \\
\hline 7 & $\begin{array}{c}\text { Lanting Yayuan Suguo } \\
\text { Supermarket(7) }\end{array}$ & 714 & $\begin{array}{c}\text { Lanting Yayuan Suguo } \\
\text { Supermarket(7) }\end{array}$ & 720 \\
\hline 8 & Shengli Village East(8) & 700 & $\begin{array}{c}\text { Jiangsu Province Hospital on } \\
\text { Integration of Chinese and Western } \\
\text { Medicine West(6) }\end{array}$ & 673 \\
\hline 9 & Hongshan Zoo North(9) & 681 & $\begin{array}{c}\text { Xiaozhuang International Plaza } \\
\text { West(5) }\end{array}$ & 646 \\
\hline 10 & Mufu Mountain Villa(10) & 608 & Hongshan Zoo North(9) & 643 \\
\hline
\end{tabular}

Table 6. The bottom ten stations of the PBN of Qixia District.

\begin{tabular}{ccccc}
\hline No. & Station & In-Strength & Station & Out-Strength \\
\hline 1 & Jinyuan Department Store East(1) & 105 & Jinyuan Department Store East(1) & 89 \\
2 & Social Security Administration of & 106 & Traffic bureau of Qixia South(4) & 106 \\
& Qixia District(2) & & Social Security Administration of & 119 \\
3 & Wanshou Garden North(3) & 117 & Qixia District(2) & 122 \\
4 & Traffic bureau of Qixia South(4) & 155 & Wanshou Garden North(3) & 152 \\
5 & Jinqu Village East(5) & 161 & Jinqu Village East(5) & 180 \\
6 & Dafa Yanlanwan West(6) & 166 & Dafa Yanlanwan West(6) & 235 \\
7 & Yanhua Garden North(7) & 226 & Yanziji Park(9) & 245 \\
8 & Gaoli Auto Parts Company East(8) & 238 & Yanhua Garden North(7) & 266 \\
9 & Yanziji Park(9) & 248 & Industrial and Commercial Bureau \\
10 & Industrial and Commercial Bureau & 262 & Gaoli Auto Parts Company East(8) & 285 \\
\hline
\end{tabular}

The stations with strong or weak strength in the PBNs had a clear division in the distribution. Areas where supermarkets, residential areas, schools, and subway stations were gathered were always areas with high demand for public bicycles. The usage of public bicycles at a station was not only related to the concentration of social and economic activities but also affected by the usage of bicycles at stations nearby.

\subsection{The Analysis of Radiation Distance}

The actual distances between stations were calculated based on longitude and latitude of the stations. The average radiation distance of the PBN of Gulou District was $1.59 \mathrm{~km}$, which was consistent with the original intention of "the first and last mile". Because of the dense distribution of public bicycle stations in Gulou District, it was easier to obtain public bicycle services in shorter distances. Furthermore, $11.3 \%$ of the cycling distances were more than $3 \mathrm{~km}, 0.13 \%$ were more than $10 \mathrm{~km}$, and the maximum distance was $17 \mathrm{~km}$, which indicated that public bicycles were not only used for short-distance travel but also for long-distance travel because of convenience, economy, and exercise purposes. 
The average radiation distance of the PBN of Qixia District was $1.87 \mathrm{~km}$, which was longer than that of Gulou District. According to the records, 15\% of the cycling distances were more than $3 \mathrm{~km}$ and the proportion at Yanziji Park Station was even more than 30\%. In fact, the area of Qixia District was seven times that of Gulou District, and there were fewer stations in Qixia District, which led to more long-distance cycling.

\subsection{The Analysis of Community Structure}

According to Louvain algorithm, the PBN of Gulou District was divided into five communities numbered 1 to 5. As explained in network construction, the PBN of Gulou District also contained stations in other districts that had bicycle renting and returning with stations in Gulou District. In order to understand the relationship between public bicycle stations within Gulou District, we removed stations in other districts, only leaving stations in Gulou District (see Figure 7).

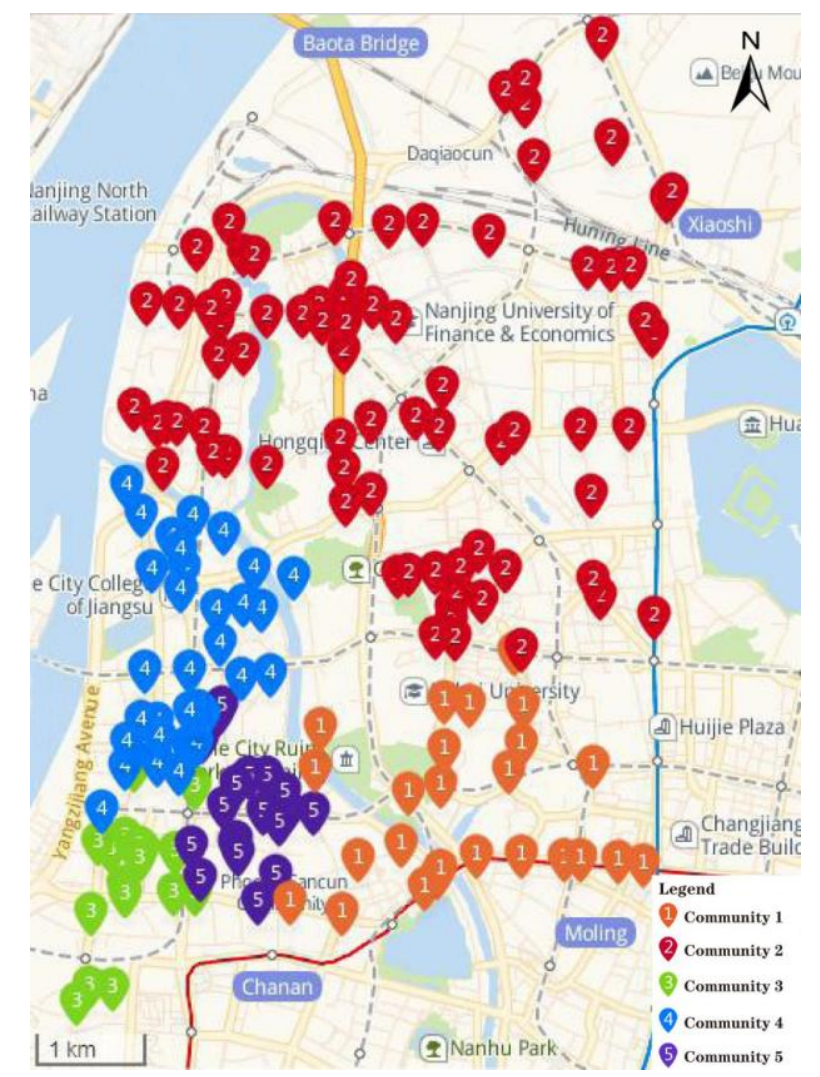

Figure 7. The community distribution of the PBN of Gulou District.

Community 1 marked in orange was located in the southeast of Gulou District. This community was around Xinjiekou Huaqiao Road area, which is an important business district in Gulou District mentioned above and also an area with some strong strength stations. There were a few stations in this community, and the stations were sparsely distributed. There were no stations with weak strength, which indicated that Community 1 was an active one for the use of public bicycles.

Community 2 marked in red was located in the north of Gulou District. It contained the most stations, which were sparsely distributed. More than $90 \%$ of these stations had weaker strength than the average, which showed that Community 2 was mainly composed of stations with lower usage of public bicycles. No. 5 Ningxia Road Station, Tianfeigong Primary School Station, and other stations within the bottom ten stations in Table 3 belonged to this community. 
Community 3 marked in green was located in the southwest of Gulou District. There were a few stations, and $70 \%$ of them had stronger strength than the average. This community contained many key stations, forming an area with high demand for public bicycles.

Community 4 marked in blue was located in the west of Gulou District. There were many stations and $65 \%$ of them had weaker strength than the average. The usage of public bicycles of Community 4 was only higher than that of Community 2.

Community 5 marked in purple was adjacent to Community 1, Community 3, and Community 4. It contained the fewest stations, which were densely distributed. Qingliangmen Suguo Supermarket Station, the station with maximum strength of the network, belonged to this community. Furthermore, Lixue Primary School Station, Huayang Jiayuan North Gate Station, and Jinxin Garden North Gate Station, which contributed the most to the strength of Qingliangmen Suguo Supermarket Station, also belonged to this community. Community 5 was an active one for the use of public bicycles.

Consistent with the analysis of Figure 5, the inactive Community 2 and Community 4 were in the north of Metro Line 4, while the active Community 1, Community 3, and Community 5 were in the south. The significant difference in the geographical distribution of communities confirmed that the stations with strong strength tended to cluster with stations with strong strength, and vice versa.

The PBN of Qixia District was divided into four communities (see Figure 8). Community 2 marked in orange had the most use of public bicycles, and Gate 1 of Maigaoqiao Subway Station belonged to this community. Community 4 marked in blue had the least use. Due to small population density, vast geographical area, and sparse stations, the usage of public bicycles was significantly lower than that of Gulou District. How to improve usage is an important issue for system operators.

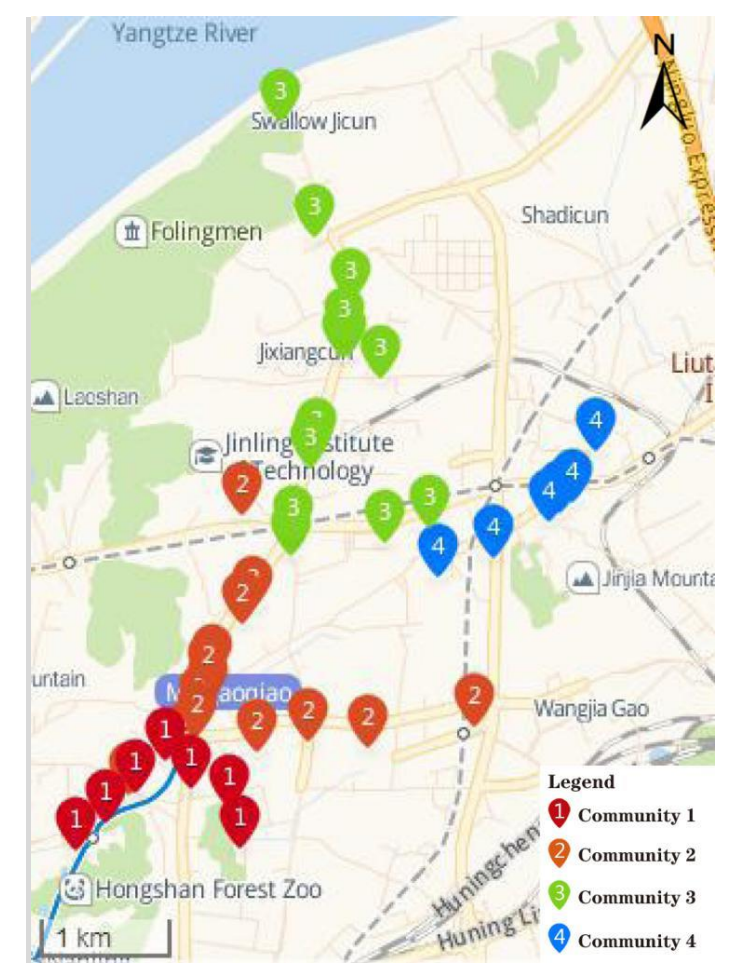

Figure 8. The community distribution of the PBN of Qixia District.

\section{Conclusion}

Based on complex network theory and geographic visualization method, we constructed the regional PBNs using Gephi software and analyzed degree, strength, radiation distance, and community structure to understand the internal relationship of the PBSs, and we got the following conclusions: 
(1) We may understand the usage of Nanjing PBS through the analysis of degree distribution and strength. The degree distribution followed the power-law distribution with the power exponents between 1 to 2, and there were still many stations with low usage of public bicycles.

(2) We understand the usage of stations and their internal relationship through the analysis of strength and community structure. Stations with strong or weak strength had a clear geographical distribution, and the cycling flow at stations in different areas varied greatly. The areas with more social and economic activities were also the areas with more use of public bicycles [7], which was confirmed again by our regional study using complex network analysis. We also found that the usage of public bicycles at some stations was not only related to land use but also related to the usage of bicycles at stations nearby.

(3) We understand the role of public bicycles through the analysis of radiation distance and strength. The average radiation distance of the PBS was consistent with the original design intention of "the first and last mile", and cycling distance was greater in remote areas. The observed data showed that public bicycles were not only served for short-distance travel but also long-distance travel. Cycling between residential areas and subway stations, between residential areas and supermarkets, was very common, and subway stations were important origin-destination stations of public bicycles.

Changes in the structure of PBNs over time will be studied in the future.

Author Contributions: Conceptualization, Y.Y.; Data curation, L.T.; Project administration, Y.Y.; Supervision, Y.Y.; Visualization, N.Z.; Writing - original draft, Y.Z.; Writing - review \& editing, Y.Y., Z.L. and M.W.

Funding: The research is supported partially by the following: The National Natural Science Foundation of China (71690242, 71503132, 71811520710), the National Social Science Fund of China (No.18BTJ040), Qing Lan Project of Jiangsu Province, China (2017), Six talent peaks project in Jiangsu Province, China (JY-055), China Postdoctoral Science Foundation (2013M541697).

Conflicts of Interest: The authors declare no conflict of interest.

\section{References}

1. DeMaio, P. Bike sharing: History, impacts, models of provision, and future. J. Public Transp. 2009, 12, 41-56. [CrossRef]

2. Fishman, E.; Washington, S.; Haworth, N.; Mazzei, A. Barriers to bikesharing: An analysis from Melbourne and Brisbane. J. Transp. Geogr. 2014, 41, 325-337. [CrossRef]

3. Vogel, M.; Hamon, R.; Lozenguez, G.; Merchez, L.; Abry, P.; Barnier, J.; Borgnat, P.; Flandrin, P.; Mallon, I.; Robardet, C. From bicycle sharing system movements to users: A typology of Vélo'v cyclists in Lyon based on large-scale behavioural dataset. J. Transp. Geogr. 2014, 41, 280-291. [CrossRef]

4. Goodman, A.; Cheshire, J. Inequality in the London bicycle sharing system revisited: Impacts of extending the scheme to poorer areas but then doubling prices. J. Transp. Geogr. 2014, 41, 272-279. [CrossRef]

5. Shaheen, S.A.; Cohen, A.P.; Martin, E.W. Public bike sharing in north America: Early operator understanding and emerging trends. Transp. Res. Rec. J. Transp. Res. Board. 2013, 2387, 83-92. [CrossRef]

6. Barbour, N.; Zhang, Y.; Mannering, F. A statistical analysis of bike sharing usage and its potential as an auto-trip substitute. J. Transp. Health 2019, 12, 253-262. [CrossRef]

7. Yao, Y.; Jiang, X.; Li, Z. Spatiotemporal characteristics of green travel: A classification study on a public bicycle system. J. Clean. Prod. 2019, 238, 117892. [CrossRef]

8. Buck, D.; Buehler, R.; Happ, P.; Rawls, B.; Chung, P.; Borecki, N. Are bikeshare users different from regular cyclists? Transp. Res. Rec. J. Transp. Res. Board. 2013, 2387, 112-119. [CrossRef]

9. Rixey, R. Station-level forecasting of bike sharing ridership: Station network effects in three U.S. systems. Transp. Res. Rec. J. Transp. Res. Board. 2013, 2387, 46-55. [CrossRef]

10. Woodcock, J.; Tainio, M.; Cheshire, J.; O'Brie, O.; Goodman, A. Health effects of the London bicycle sharing system: Health impact modeling study. Br. Med. J. 2014, 348, g425. [CrossRef] [PubMed] 
11. Corcoran, J.; Li, T.B.; Rohde, D.; Charles-Edwards, E.; Mateo-Babiano, D. Spatio-temporal patterns of a Public Bicycle Sharing Program: The effect of weather and calendar events. J. Transp. Geogr. 2014, 41, 292-305. [CrossRef]

12. Faghih-Imani, A.; Eluru, N.; El-Geneidy, A.M.; Rabbat, M.; Haq, U. How land-use and urban form impact bicycle flows: Evidence from the bicycle-sharing system (BIXI) in Montreal. J. Transp. Geogr. 2014, 41, 306-314. [CrossRef]

13. El-Assi, W.; Mahmoud, M.S.; Habib, K.N. Effects of built environment and weather on bike sharing demand: A station level analysis of commercial bike sharing in Toronto. Transportation 2017, 44, 589-613. [CrossRef]

14. Buck, D.; Buehler, R. Bike lanes and other determinants of capital bike share trips. In Proceedings of the Transportation research board 91st annual meeting, Washington, DC, USA, 22-26 January 2012.

15. Wang, X.; Lindsey, G.; Schoner, J.E.; Harrison, A. Modeling bike share station activity: Effects of nearby businesses and jobs on trips to and from stations. J. Urban Plann. Dev. 2016, 142, 4015001. [CrossRef]

16. Wang, Y.; Chau, C.K.; Ng, W.Y.; Leung, T.M. A review on the effects of physical built environment attributes on enhancing walking and cycling activity levels within residential neighborhoods. Cities 2016, 50, 1-15. [CrossRef]

17. Faghih-Imani, A.; Hampshir, R.; Lavanya, M.; Eluru, N. An empirical analysis of bike sharing usage and rebalancing: Evidence from Barcelona and Seville. Transp. Res. A. 2017, 97, 177-191. [CrossRef]

18. Luo, S.; Zhen, F.; Yin, Q. How Built Environment Influence Public Bicycle Usage: Evidence from the Bicycle Sharing System in Qiaobei Area, Nanjing. Sci. Geogr. Sin. 2018, 38, 332-341. [CrossRef]

19. Liu, H.C.; Lin, J.J. Associations of built environments with spatiotemporal patterns of public bicycle use. J. Transp. Geogr. 2019, 74, 299-312. [CrossRef]

20. Martin, E.W.; Shaheen, S.A. Evaluating public transit modal shift dynamics in response to bikesharing: A tale of two U.S. cities. J. Transp. Geogr. 2014, 41, 315-324. [CrossRef]

21. Ma, T.; Liu, C.; Erdoan, S. Bicycle sharing and public transit: Does capital bike share affect metrorail ridership in Washington, D.C. Transp. Res. Rec. J. Transp. Res. Board 2015, 2534, 1-9. [CrossRef]

22. Klingen, J. Do metro interruptions increase the demand for public rental bicycles? Evidence from Paris. Transp. Res. Part A 2019, 123, 216-228. [CrossRef]

23. Gu, T.Q.; Kim, I.; Currie, G. Measuring immediate impacts of a new mass transit system on an existing bike-share system in China. Transp. Res. Part A 2019, 124, 20-39. [CrossRef]

24. Li, W.Y.; Tian, L.X.; Gao, X.Y.; Batool, H. Effects of dockless bike-sharing system on public bike system: Case study in Nanjing, China. Energy Procedia 2019, 158, 3754-3759. [CrossRef]

25. Fishman, E.; Washington, S.; Haworth, N. Bike share: A synthesis of the literature. Transp. Rev. 2013, 33, 148-165. [CrossRef]

26. Fishman, E.; Washington, S.; Haworth, N. Bike share's impact on car use Evidence from the United States, Great Britain, and Australia. Transp. Res. Part D 2014, 31, 13-20. [CrossRef]

27. Shaheen, S.; Martin, E.; Cohen, A.P.; Finson, R. Public Bikesharing in North America: Early Operator and User Understanding; Mineta Transportation Institute: San Jose, CA, USA, 2012.

28. Shaheen, S.A.; Martin, E.W.; Chan, N.D.; Cohen, A.P.; Pogodzinski, M. Public Bikesharing in North America during a Period of Rapid Expansion: Understanding Business Models, Industry Trends and User Impacts; Mineta Transportation Institute: San Jose, CA, USA, 2014.

29. Chen, J.; Zhang, Y.; Zhang, R.; Cheng, X.; Yan, F.Y. Analyzing users' attitudes and behavior of free-floating bike sharing: An investigating of Nanjing. Transp. Res. Procedia 2019, 39, 634-645. [CrossRef]

30. Fuller, D.; Luan, H.; Buote, R.; Auchinclossd, A.H. Impact of a public transit strike on public bicycle share use: An interrupted time series natural experiment study. J. Transp. Health 2019, 13, 137-142. [CrossRef]

31. Saberi, M.; Ghamami, M.; Gu, Y.; Shojaei, M.H.; Fishman, E. Understanding the impacts of a public transit disruption on bicycle sharing mobility patterns: A case of Tube strike in London. J. Transp. Geogr. 2018, 66, 154-166. [CrossRef]

32. Bachand-Marleau, J.; Lee, B.H.Y.; El-Geneidy, A.M. Better understanding of factors influencing likelihood of using shared bicycle systems and frequency of use. Transp. Res. Rec. J. Transp. Res. Board. 2012, 2314, 66-71. [CrossRef]

33. Luo, H.; Kou, Z.Y.; Zhao, F.; Cai, H. Comparative life cycle assessment of station-based and dock-less bike sharing systems. Resour. Conserv. Recycl. 2019, 146, 180-189. [CrossRef] 
34. Fricker, C.; Gast, N. Incentives and Redistribution in Homogeneous Bike-Sharing Systems with Stations of Finite Capacity. Euro J. Transp. Logist. 2016, 5, 261-291. [CrossRef]

35. Chemla, D.; Meunier, F.; Wolfler Calvo, R. Bike sharing systems: Solving the static rebalancing problem. Discr. Optim. 2013, 10, 120-146. [CrossRef]

36. Alvarez-Valdes, R.; Belenguer, J.M.; Benavent, E.; Bermudez, J.D.; Muñoz, F.; Vercher, E.; Verdejo, F. Optimizing the level of service quality of a bikesharing system. Omega 2016, 62, 163-175. [CrossRef]

37. Ghosh, S.; Varakantham, P.; Adulyasak, Y.; Jaillet, P. Dynamic repositioning to reduce lost demand in bike sharing systems. J. Artif. Intell. Res. 2017, 58, 387-430. [CrossRef]

38. Park, C.; Young Sohn, S. An Optimization Approach for the Placement of Bicycle-sharing stations to Reduce Short Car Trips: An Application to the City of Seoul. Transp. Res. Part A 2017, 105, 154-166. [CrossRef]

39. Ho, S.C.; Szeto, W.Y. A hybrid large neighborhood search for the static multivehicle bike-repositioning problem. Transp. Res. Part B 2017, 95, 340-363. [CrossRef]

40. Zhang, D.; Yu, C.; Desai, J.; Lau, H.Y.K.; Srivathsan, S. A time-space network flow approach to dynamic repositioning in bicycle sharing systems. Transp. Res. Part B. 2017, 103, 188-207. [CrossRef]

41. Scarinci, R.; Markov, I.; Bierlaire, M. Network design of a transport system based on accelerating moving walkways. Transp. Res. Part C. 2017, 80, 310-328. [CrossRef]

42. Cruz, F.; Subramanian, A.; Bruck, B.P.; Iori, M. A heuristic algorithm for a single vehicle static bike sharing rebalancing problem. Comput. Oper. Res. 2017, 79, 19-33. [CrossRef]

43. Legros, B. Dynamic repositioning strategy in a bike-sharing system; how to prioritize and how to rebalance a bike station. Eur. J. Oper. Res. 2019, 272, 740-753. [CrossRef]

44. Feng, Y.L.; Affonso, R.C.; Zolghadri, M. Analysis of bike sharing system by clustering: The Velib' case. IFAC PapersOnLine 2017, 50, 12422-12427. [CrossRef]

45. Froehlich, J.; Neumann, J.; Oliver, N. Sensing and predicting the pulse of the city through shared bicycling. Int. Joint Conf. Artif. Intell. 2009, 9, 1420-1426.

46. Come, E.; Oukhellou, L. Model-based count series clustering for bike sharing system usage mining: A case study with the Velib' system of Paris. ACM Trans. Intell. Syst. Technol. 2014, 5, 39-65. [CrossRef]

47. Zhou, X. Understanding spatiotemporal patterns of biking behavior by analyzing massive bike sharing data in Chicago. PLoS ONE 2015, 10, 1-20. [CrossRef] [PubMed]

48. Borgnat, P.; Abry, P.; Flandrin, P.; Robardet, C.; Rouquier, J.B.; Fleury, E. Shared bicycles in a city: A signal processing and data analysis perspective. Adv. Complex Syst. 2011, 14, 415-438. [CrossRef]

49. Austwick, M.Z.; O’Brien, O.; Strano, E.; Viana, M. The structure of spatial networks and communities in bicycle sharing systems. PLoS ONE 2013, 8, e74685. [CrossRef]

50. Lin, L.; He, Z.; Peeta, S. Predicting station-level hourly demand in a large-scale bike-sharing network: A graph convolutional neural network approach. Transp. Res. Part C: Emerg. Technol. 2018, 97, 258-276. [CrossRef]

51. Nanjing Statistics Bureau, Survey Office of the National Bureau of Statistics in Nanjing. Statistical Yearbook of Nanjing; China Statistics Press: Beijing, China, 2017.

52. Banerjee, A.; Chandrasekhar, A.G.; Duflo, E.; Jackson, M.O. The diffusion of microfinance. Science 2013, 341, 1236498. [CrossRef]

53. Kim, H.J.; Lee, Y.; Kahng, B.; Kim, I.M. Weighted scale free network in financial correlations. J. Phys. Soc. Jpn. 2002, 71, 2133-2136. [CrossRef]

54. Onnela, J.P.; Kaski, K.; Kertesz, J. Clustering and information in correlation based financial networks. Eur. Phys. J. B 2004, 38, 353-362. [CrossRef]

55. Yang, Y.; Liu, Y.; Zhou, M.; Li, F.; Sun, C. Robustness assessment of urban rail transit based on complex network theory: A case study of the Beijing Subway. Saf. Sci. 2015, 79, 149-162. [CrossRef]

56. Zhang, X.; Ren, Y.; Huang, B.; Han, Y. Analysis of time-varying characteristics of bus weighted complex network in Qingdao based on boarding passenger volume. Phys. A Stat. Mech. Appl. 2018, 506, 376-394. [CrossRef]

57. Hossain, M.M.; Alam, S. A complex network approach towards modeling and analysis of the Australian Airport Network. J. Air Transp. Manag. 2017, 60, 1-9. [CrossRef]

58. Fichera, A.; Frasca, M.; Volpe, R. Complex networks for the integration of distributed energy systems in urban areas. Appl. Energy 2017, 193, 336-345. [CrossRef] 
59. Tsolas, S.D.; Karim, M.N.; Hasan, M.F. Optimization of water-energy nexus: A network representation-based graphical approach. Appl. Energy 2018, 224, 230-250. [CrossRef]

60. Wang, M.; Chen, Y.; Tian, L.; Jiang, S.; Tian, Z.; Du, R. Fluctuation behavior analysis of international crude oil and gasoline price based on complex network perspective. Appl. Energy 2016, 175, 109-127. [CrossRef]

61. Zhang, W.B.; Tian, L.X.; Yao, Y.; Tian, Z.H.; Wang, M.G.; Zhang, G.Y. Dynamic evolution characteristics of European union emissions trade system price from high price period to low price period. J. Clean. Prod. 2019, 224, 188-197. [CrossRef]

(C) 2019 by the authors. Licensee MDPI, Basel, Switzerland. This article is an open access article distributed under the terms and conditions of the Creative Commons Attribution (CC BY) license (http://creativecommons.org/licenses/by/4.0/). 